\title{
STUDI LIVING QUR'AN TENTANG PENGARUH PEMBACAAN SURAT AL-FATIHAH BAGI ANAK YANG SERING TANTRUM
}

\author{
Desty Angga Wulan ${ }^{1}$, Musyarapah ${ }^{2}$ \\ ${ }^{1}$ IAIN Palangka Raya, destydarkness@gmail.com \\ ${ }^{2}$ IAIN Palangka Raya, musyarapah@iain-palangkaraya.ac.id
}

\begin{abstract}
Abstrak
Dinamakan Al-Fatihah karena menjadi pembuka Al-Qur'an. Al-Fatihah memiliki nama lain Ash-Syifa yang artinya obat penawar atau penyembuh. Di sini Al-Fatihah digunakan sebagai ikhtiar untuk mengobati anakanak yang sering tantrum. Jadi pokok masalah di sini adalah bagaimana pengaruh pembacaan surat AlFatihah pada anak-anak yang sering tantrum. Penulis mengambil contoh pada anak-anak yang ibunya mengikuti pengajian setiap Jum'at di Desa Sungai Kapitan, Kecamatan Kumai, Kotawaringin Barat. Artikel ini bertujuan sebagai pengetahuan untuk para ibu yang ketika anaknya tantrum atau dalam fase emosional atau sering mengamuk, bisa menerapkan pembacaan surat Al-Fatihah sebagai penyembuhnya. Pengobatan tidak harus berupa obat secara secara fisik seperti obat-obatan kimia. Pengobatan bisa dengan pengobatan secara batin. Tantrum tidak hanya terjadi pada anak usia di bawah tiga tahun. Bisa juga terjadi pada anak Sekolah Dasar atau remaja. Jenis penelitian ini adalah deskriptif kualitatif, yaitu data yang dikumpulkan berbentuk kata-kata, gambar, bukan angka-angka. Penulis melakukan pengamatan dan berperan sebagai participant observation aktif, mewawancarai informan dan dokumentasi. Kemudian menganalisis dan mereduksi data yang sudah diperoleh dari lapangan. Hasil penelitian ini adalah emosi anak bisa stabil dan lebih tenang setelah dibacakan surat Al-Fatihah, meningkatkan konsentrasi belajar dan mencerdaskan anak, anak mampu berinteraksi, anak lebih mandiri, anak lebih ceria dan jarang menangis, anak bersikap lebih positif, sistem kekebalan tubuhnya semakin baik.
\end{abstract}

Kata Kunci : Pengaruh, Al-Fatihah, Anak Tantrum

\begin{abstract}
Called Al-Fatihah because it is the opening of the Qur'an. Al-Fatihah has another name ash-syifa which means antidote or healer. Al-Fatihah is used as an effort to treat children who often have tantrums. So, the main problem here is how the effect of reading Surah Al-Fatihah on children who often have tantrums. The author take the example of children whose mothers attend recitationsevery Friday in Sungai Tendang Village, Kumai District, Kotawaringin Barat. This article aims as knowledge for mothers who when their child has a tantrum or is in an emotional phase or often tantrums, can apply the recitation of Surah Al-Fatihah as a healer. The treatment does not have to be physical drugs such as chemical drugs. Treatment can be with inner medicine. Tantrums do not only occur in children under three years of age. Can also occur in elementary school children or teenagers. This type of research is descriptive qualitative, ie the data collected is in the form of words, pictures, not numbers. The writer makes observations and acts as an active participant of observation, interviewing information and documentation. Then analyze and reduce the data that has been obtained from the location. The result of this study is that children's emotion can be stable and calmer after reading surah Al-Fatihah, improve learning concentration and educate children, children are able to
\end{abstract}

Al Qalam: Jurnal Ilmiah Keagamaan dan Kemasyarakatan Vol. 16, No. 2

$$
\text { Maret - April } 2022
$$


Desty Angga Wulan, Musyarapah : Studi Living Qur'an Tentang Pengaruh Bacaan Surah Al-Fatihah Bagi Anak Yang Sering Tantrum

interact, children are more independent, children are more cheerful and cry less, their attitude is more positive, the immune system is getting better.

Key words : Influence, Al-Fatihah, Child tantrums.

\section{PENDAHULUAN}

Secara konsep, tantrum adalah hal yang baru bagi kebanyakan orangtua, padahal pada kenyataannya perilaku ini adalah hal yang wajar dialami oleh orangtua dalam pengasuhan anak. Perilaku tantrum adalah perilaku yang normal. Ini terjadi karena ketidaknyaman yang dirasakan oleh anak dengan beberapa sebab seperti lapar, ngantuk, sakit, keinginannya terhalangi, orang tua salah merespon kebutuhan anak, diserang atau dikritik, dirampas permainannya atau bertemu dengan orang asing dan beberapa sebab lainnya. Pola pengasuhan yang tidak konsisten juga berkontribusi besar terhadap perilaku ini termasuk jika orang tua terlalu memanjakan dan menuruti keinginan anak. Karena ini adalah perilaku normal, maka orang tua perlu meresponnya secara tepat dan proporsional.

Tantrum ini biasanya muncul pada anak usia 1 sampai 4 tahun. Hal ini merupakan hal yang wajar karena anak belum bisa mengendalikan emosi dalam suasana yang penuh tekanan karena bingung, bosan, putus asa dan berlangsung selama 10-15 menit lalu kondisi perilaku serta emosi kembali membaik ketika tantrum mereda. Sekitar 5-7\% anak antara 1-3 tahun memiliki kemarahan yang berlangsung setidaknya 15 menit tiga kali atau lebih per minggu. Sekitar $20 \%$ anak usia 2 tahun, $18 \%$ anak usia 3 tahun dan $10 \%$ anak usia 4 tahun memiliki setidaknya satu periode emosi setiap hari. ${ }^{1}$ Hal ini karena anak pada usia segitu belum bisa mengelola emosi dan mengutarakan kesukaran yang dihadapinya.

Tetapi tantrum dikatakan tidak normal apabila terjadi lima kali dalam sehari dan terjadi lebih dari 15 menit. Kondisi tantrum yang berlangsung lama dan disertai perilaku yang impulsivitas (sikap ketika seseorang melakukan suatu tindakan tanpa memikirkan akibat dari apa yang dilakukannya), agresifitas, menentang, merusak yang bersifat menetap adalah kondisi patologis anak yang memerlukan penanganan segera agar terhindar dari segala resiko cedera anak dan ketegangan keluarga. ${ }^{2}$ Biasanya anak yang terlalu lama tantrum itu kehilangan energi lebih banyak, minat, hilang nafsu makan karena terlalu lelah, sulit berkonsentrasi dan menyebabkan menurunnya imunitas pada anak.

${ }^{1}$ Izzatul Fithriyah, Yunias Setiawati, Sasanti Yuniar, "Mengatasi Temper Tantrum Pada Anak Prasekolah" (Universitas Airlangga, 2019). Hal. 10

${ }^{2}$ Izzatul Fithriyah, Yunias Setiawati, Sasanti Yuniar. Hal. 11.

Al Qalam: Jurnal Ilmiah Keagamaan dan Kemasyarakatan Vol. 16, No. 2

Maret - April 2022 
Desty Angga Wulan, Musyarapah : Studi Living Qur'an Tentang Pengaruh Bacaan Surah Al-Fatihah Bagi Anak Yang Sering Tantrum

Salah satu penanganan untuk anak tantrum adalah dengan terapi yaitu pembacaan surahsurah dalam Al-Qur'an, salah satunya surah Al-Fatihah. Al-Qur'an merupakan obat bagi penyakit fisik dan spiritual. Hal ini seperti yang dijelaskan dalam Q.S. Al-Isra : 82 sebagai berikut.

Artinya : "Dan Kami turunkan dari Al-Qur'an suatu yang menjadi penawar dan rahmat bagi orang-orang yang beriman dan Al-Qur'an itu tidaklah menambah kepada orang-orang yang dzalim selain kerugian.”( Q.S. Al-Isra : 82)

Surah Al-Fatihah adalah surah yang bisa dikatakan paling mudah karena surah Al-Fatihah itu adalah surah yang harus dihafal ketika sholat. Al-Fatihah merupakan surah pertama yang dibaca ketika sholat sehingga ketika sholat dan kita tidak membaca Al-Fatihah maka sholatnya tidak sah. Hal ini menunjukkan bahwa betapa tingginya kedudukan Al-Fatihah ini.

Kita bisa memetik hikmah dari sebuah cerita zaman Nabi yang berkaitan dengan Al-Fatihah sebagai Asy-Syifa. Rasulullah pernah mengirimkan pasukan berjumlah tiga puluh. Mereka tiba di sebuah perkampungan. Mereka ingin dijamu sebagai tamu, namun tak ada orang yang mau menjamu. Pada saat yang sama pemimpin kaum mereka digigit ular. Mereka meminta bantuan pada sahabat untuk mengobatinya. Abu Sa'id Al-Khudri bersedia mengobatinya, dengan syarat mereka membayar dengan tiga puluh ekor kambing. Kemudian Abu Sa'id Al-Khudri menghampiri pemimpin kaum tersebut yang digigit ular, dan mengobatinya dengan cara dibacakan surah AlFatihah sebanyak 3 kali. Pemimpin itu sembuh. Abu Sa'id Al-Khudri membawa kambing 30 ekor tapi sahabat menolak. Para sahabat bertanya, "Engkau menerima upah dari membaca kitab Allah?" Ketika sampai di Madinah mereka menceritakan hal tersebut kepada Nabi Muhammad. "Silakan bagikan upah tersebut di antara kalian. Tak ada yang pantas kalian ambil upahnya seperti kitab Allah," sabda Nabi Muhammad. Dari cerita tersebut dapat kita ambil hikmah dan kesimpulan AlFatihah merupakan penawar dari segala penyakit, baik penyakit hati maupun penyakit fisik.

Yang menjadi pertanyaan ketika ada orang meruqyah orang lain atau dirinya sendiri tetapi dia tidak sembuh dari penyakitnya, maka yang salah ayatnya atau diri kita yang salah? Sesungguhnya kesembuhan orang ketika dibacakan ayat-ayat Al-Qur'an itu bergantung dari kadar keimanan seseorang. Itu semua hanya ikhtiar kita sebagai manusia untuk meminta kesembuhan dari Allah, asalkan tidak bertentangan dengan akidah Islam.

Berdasarkan pemikiran dan latar belakang yang dikemukakan di atas, maka Penulis tertarik membuat artikel yang berjudul “Studi Living Qur'an Tentang Pengaruh Pembacaan Surah AlFatihah Bagi Anak Yang Sering Tantrum.

Al Qalam: Jurnal Ilmiah Keagamaan dan Kemasyarakatan Vol. 16, No. 2 Maret - April 2022 
Desty Angga Wulan, Musyarapah : Studi Living Qur'an Tentang Pengaruh Bacaan Surah Al-Fatihah Bagi Anak Yang Sering Tantrum

\section{METODE PENELITIAN}

Metode penelitian pada artikel ini adalah metode penelitian kualitatif dan sering disebut metode penelitian naturalistik karena penelitiannya dilakukan pada kondisi atau obyek yang alamiah. Obyek alamiah adalah obyek yang berkembang apa adanya, tidak dimanipulasi oleh peneliti dan kehadiran peneliti tidak mempengaruhi dinamika pada obyek tersebut. ${ }^{3}$ Metode pengumpulan data dengan observasi, wawancara informan dan dokumentasi.

\section{ANALISIS DAN PEMBAHASAN}

Secara etimologis, living berasal dari bahasa Inggris live yang artinya hidup, aktif dan yang hidup, yang mendapat tambahan kata kerja -ing yang difungsikan sebagai ajektif dalam bentuk present participle, maka akan bermakna Al-Qur'an yang hidup. ${ }^{4} \mathrm{Al}-\mathrm{Qur}$ 'an dihidupkan oleh sahabat dengan cara menghidupkan sunnah nabi, yaitu menghidupkan tradisi kenabian, meneladani serta mengikuti jejak Rasulullah. Bagi sahabat yang hidup di jaman nabi biasanya akan menyaksikan dan bergaul dengan Nabi, sehingga terlihat dari karakter dan cara mereka mengobati suatu penyakit akan cenderung meniru Nabi Muhammad.

Tantrum bisa dikatakan perilaku yang sering dan wajar terjadi pada anak-anak ditandai dengan luapan emosi dan perilaku yang berlebihan akibat kemarahan dan kondisi frustasi anak dengan gejala klinis sikap keras kepala, menentang, membangkang, melawan, memberontak, marah, berkata-kata kasar, menangis, menjerit, berteriak, berguling-guling, menendang, membenturkan kepala ke tembok, membuang benda-benda yang ada di dekatnya, melempari batu orang-orang yang ada di dekatnya, menarik rambut, memukul, membantingkan badan ke lantai karena emosi sulit dikendalikan dan dikelola dan perilaku itu mengakibatkan distress orang tua dan lingkungan.

Perilaku tantrum biasanya muncul karena anak belum mampu mengutarakan keinginan dan tujuan yang ingin dicapainya karena perkembangan otaknya yang belum matang. Anak usia pra sekolah dengan energi tinggi meluapkan kekesalan dengan perilaku tantrum. Tetapi tantrum juga tidak sebatas anak pra sekolah. Ada anak remaja bahkan orang dewasa yang masih tantrum. Namun hal ini sudah sangat jarang karena orang dewasa biasanya sudah bisa mengelola emosinya.

Mengidentifikasi lima jenis tantrum yang dapat menyebabkan gangguan pada perilaku anak, yaitu perilaku agresif pada pengasuh, melukai diri sendiri, adanya episode tantrum 10 sampai 20

${ }^{3}$ Sugiyono, Metode Penelitian Kuantitatif Kualitatif Dan $R \& D$, Cet. 2 (Bandung: CV. Alfabeta, 2019). Hal. 17

${ }^{4}$ Dr. Ahmad 'Ubaydi Hasbillah, MA. Hum, Ilmu Living Qur'an-Hadis Ontologi. Epistemologi Dan Aksiologi, Cet. 3 (Banten: Yayasanl Wakaf Darus-Sunnah, 2021). Hal. 22.

Al Qalam: Jurnal Ilmiah Keagamaan dan Kemasyarakatan Vol. 16, No. 2

Maret - April 2022 
Desty Angga Wulan, Musyarapah : Studi Living Qur'an Tentang Pengaruh Bacaan Surah Al-Fatihah Bagi Anak Yang Sering Tantrum

kali di rumah dan di sekolah dalam waktu 30 hari, atau lebih dari 5 kali dalam sehari di rumah atau sekolah, perilaku tantrum yang terus-menerus selama 25 menit dan tantrum yang tidak bisa ditenangkan. Perilaku dengan tantrum tersebut bisa menyebabkan gangguan mental yang memerlukan penanganan di pusat kesehatan mental anak dan remaja. ${ }^{5}$

Diriwayatkan dari Abu Sa'id bin Mu'alla: Aku sedang sholat. Rasulullah memanggilku tetapi aku tidak tidak menjawabnya, hingga aku selesai sholat. Lalu aku datang kepadanya, dan beliau berkata, "Mengapa engkau tidak segera datang kepadaku?" Aku menjawab, "Whai Rasulullah, sesungguhnya aku sedang sholat." Lalu beliau bersabda, "Bukankah Allah SWT telah berfirman, Hai orang-orang yang beriman, penuhilah seruan Allah dan seruan Rasul apabila Rasul kalian menyeru kalian pada sesuatu yang member kehidupan kepada kalian.” (QS. Al-Anfal : 24)

Rasulullah SAW Bersabda lagi bahwa : "Sesungguhnya, aku benar-benar akan mengajarkan kepadamu surah yang paling agung dalam Al-Qur'an sebelum engkau keluar dari masjid ini.” Lalu beliau memegang tanganku. Ketika beliau hendak keluar masjid, aku bertanya, "Wahai Rasulullah, engkau telah mengatakan bahwa akan mengajarkan kepadaku sebuah surah al-Qur'an yang paling agung." Beliau menjawab, "Ya, alhamdulillahi rabbil 'alamin adalah tujuh ayat yang diulang dan al-Qur'an al-'adzim (Al-Fatihah) yang diberikan kepadaku."

Pembacaan adalah proses, cara, perbuatan membaca. Surah ini dinamai Al-Fatihah karena menjadi pembuka dalam Al-Qur'an. Al-Fatihah memiliki beberapa nama lain yaitu Ummul Kitab (induknya kitab), Ummul Qur'an (induknya Al-Qur'an), Al-Hamdu (pujian), Ash-Sholah (sholat), Asy-Syifa (obat penawar atau penyembuh), Ar-Ruqyah (jampi dari Al-Qur'an), Asasul Qur'an (fondasi dari Al-Qur'an), Al-Waqiyah (pencegah), Al-Kafiyah (mencukupi), Al-Kanz (kandungan). ${ }^{7}$ Jadi bisa disimpulkan menurut artikel ini pembacaan surah Al-Fatihah adalah proses, cara, perbuatan membaca surah Al-Fatihah sebagai Asy-Syifa (obat penawar atau penyembuh) pada perilaku tantrum anak. Apa manfaatnya? mari kita kaji di artikel ini.

Penulis mengadakan wawancara pada beberapa ibu anggota pengajian hari Jum'at di mana anaknya sering tantrum di Desa Sungai Kapitan, Kotawaringin Barat. Sungai Kapitan berada di Kecamatan Kumai, Kabupaten Kotawaringin Barat, Provinsi Kalimantan Tengah. Luas Kapitan sekitar $5.600 \mathrm{Ha}^{2}$ dan terdiri dari $12 \mathrm{RT}$, dengan kepadatan penduduk mencapai 5.661 jiwa

${ }^{5}$ Izzatul Fithriyah, Yunias Setiawati, Sasanti Yuniar, "Mengatasi Temper Tantrum Pada Anak Prasekolah." Hal. 12.

${ }^{6}$ Ibnu Katsir, Mudah Tafsir Ibnu Katsir 1 Al-Fatihah s.d. Al-Baqarah Shahih, Sistematis, Lengkap Diterjemahkan Oleh DR. Engkos Kosasih, Lc., M. Ag. (Jakarta: Maghfirah Pustaka, 2016). Hal. 4

${ }^{7}$ Ibnu Katsir. Hal. 2

Al Qalam: Jurnal Ilmiah Keagamaan dan Kemasyarakatan Vol. 16, No. 2

Maret - April 2022 
Desty Angga Wulan, Musyarapah : Studi Living Qur'an Tentang Pengaruh Bacaan Surah Al-Fatihah Bagi Anak Yang Sering Tantrum

penduduk tetap. Kapitan dapat ditempuh dalam jangka waktu kurang lebih 30 menit dari Ibu kota Kabupaten yaitu Pangkalan Bun.

Dari beberapa pengalaman orang tua yang memilik anak dengan postur tubuh yang besar dan si ibu memiliki postur tubuh yang kecil, bisa jadi ketika ibunya dipukul menyebabkan sakit atau nyeri di bagian anggota tubuh sang ibu. Hal ini dikarenakan kuatnya tenaga anak ketika mengamuk dan durasi tantrum si anak sekitar lebih dari 20 menit. Durasi ini terbilang cukup lama karena umumnya tantrum hanya berkisar 10-15 menit. Terkadang ketika anak-anak tantrum, mereka bisa merusakkan barang-barang yang berada di dekatnya dengan cara melempar, membanting ataupun membuang dengan sengaja barang-barang tersebut. Biasanya tantrum seperti ini dialami oleh anak di atas 5 tahun.

Bagi ibu-ibu yang memiliki pengalaman anak tantrum seperti di atas, mereka mulai menerapkan pembacaan surah Al-Fatihah untuk anaknya yang sering tantrum. Pengetahuan atau informasi seperti itu didapat dari pembicaraan mulut ke mulut atau pengalaman dari salah satu ibu kemudian ditularkan pada para ibu yang lain. Prosesnya yaitu si ibu menerapkan pembacaan AlFatihah setiap hari sampai batas waktu yang tidak ditentukan, di waktu pagi dan petang. Untuk pembacaan Al-Fatihah di pagi hari sebanyak minimal 42 kali atau bisa lebih dari jumlah tersebut apabila mampu dan di sore hari sebanyak minimal 42 kali. Sebelum membaca Al-Fatihah, biasanya ibu mengucapkan bahwa Al-Fatihah tersebut ditujukan untuk anaknya yang bernama fulan bin/binti fulan, berdoa agar si anak dilembutkan hatinya. Dan ini berlangsung sekitar 5 bulan dan mulai ada perubahan pada diri anak yang sering tantrum tadi. ${ }^{8}$

Anak-anak yang sudah pernah dibacakan Al-Fatihah oleh ibunya, biasanya tantrumnya tidak sebrutal sebelumnya. Mereka berangsur-angsur mulai menurut. Tantrumnya mulai berkurang. Jadi, apabila sebelumnya kuantitas tantrumnya 6-7 kali dalam sebulan, maka ketika si anak sudah dibacakan Al-Fatihah oleh sang ibu kuantitas tantrumnya menurun menjadi 3-4 kali dalam sebulan hingga hilang sama sekali. Dan nilai plusnya dari pembacaan Al-Fatihah ini, si anak yang sering tantrum biasanya imunitas tubuhnya kurang baik (sering sakit), setelah sering dibacakan Al-Fatihah oleh si ibu, anaknya lebih sehat dan jarang sakit. Si anak juga bisa berinteraksi dengan kawankawan seusianya dengan baik dan bisa cepat merespon hafalan-hafalan ayat Al-Qur'an sehingga sekarang anaknya menjadi penghafal Qur'an.

Sebagian ibu ada yang menerapkan pembacaan surah Al-Fatihah tetapi waktunya berbeda. Beberapa ibu menerapkan pembacaan Al-Fatihah pada saat mencuci beras. Maksudnya si ibu ketika

\footnotetext{
${ }^{8}$ Evi Julianur, Wawancara Tentang Penerapan Pembacaan Al-Fatihah Pada Anaknya, November 18, 2021.
}

Al Qalam: Jurnal Ilmiah Keagamaan dan Kemasyarakatan Vol. 16, No. 2

Maret - April 2022 
Desty Angga Wulan, Musyarapah : Studi Living Qur'an Tentang Pengaruh Bacaan Surah Al-Fatihah Bagi Anak Yang Sering Tantrum

mencuci beras (memutar-mutar beras searah jarum jam) sebelum dimasak, biasanya sambil membaca Al-Fatihah sebanyak 7 kali dengan harapan agar anaknya yang memakan nasi tersebut bisa dilembutkan hatinya oleh Allah. Kegiatan ini dilakukan setiap hari ketika akan memasak nasi. Bentuk tantrum dari anak si ibu ini adalah anaknya suka melempari teman-temannya dengan batu dan membuka bajunya ketika emosinya meledak-ledak. Dan dari kegiatan pembacaan Al-Fatihah yang sudah dilakukan hampir 6 bulan tadi, anak yang sering tantrum tersebut mulai berkurang kuantitas tantrumnya, anaknya sudah bisa fokus pada hal-hal yang positif misalnya sekarang suka sholawatan, tidak sering menangis lagi. ${ }^{9}$ Jadi seberapa lama pembacaan Al-Fatihah untuk anakanak yang sering tantrum ini tidak selalu sama waktunya. Ada yang pemyembuhannya cepat ada yang lama.

Jadi dapat disimpulkan study living Qur'an tentang penerapan pembacaan Al-Fatihah pada anak tantrum ini memberi banyak manfaat, yaitu :

1. Emosi anak bisa stabil dan lebih tenang setelah dibacakan surat Al-Fatihah.

2. Meningkatkan konsentrasi belajar dan mencerdaskan anak.

3. Anak mampu berinteraksi lebih baik.

4. Anak lebih mandiri.

5. Anak lebih ceria dan jarang menangis.

6. Anak bersikap lebih positif.

7. Sistem kekebalan tubuhnya semakin baik.

\section{KESIMPULAN}

Tantrum yang terjadi pada usia 1-4 tahun merupakan hal yang biasa. Karena di umur segitu anak belum bisa mengendalikan emosi dalam suasana yang penuh tekanan karena bingung, bosan, putus asa dan berlangsung selama 10-15 menit lalu kondisi perilaku serta emosi kembali membaik ketika tantrum mereda. Sekitar 5-7\% anak antara 1-3 tahun memiliki kemarahan yang berlangsung setidaknya 15 menit tiga kali atau lebih per minggu. Sekitar $20 \%$ anak usia 2 tahun, $18 \%$ anak usia 3 tahun dan $10 \%$ anak usia 4 tahun memiliki setidaknya satu periode emosi setiap hari. Hal ini karena anak pada usia segitu belum bisa mengelola emosi dan mengutarakan kesukaran yang dihadapinya.

Tantrum dikatakan tidak normal apabila terjadi lima kali dalam sehari dan terjadi lebih dari 15 menit. Kondisi tantrum yang berlangsung lama dan disertai perilaku yang impulsivitas (sikap

${ }^{9}$ Iin Mutiara, Innayah, Wawancara Tentang Penerapan Pembacaan Al-Fatihah Pada Anaknya, November 28, 2021.

Al Qalam: Jurnal Ilmiah Keagamaan dan Kemasyarakatan Vol. 16, No. 2

Maret - April 2022 
Desty Angga Wulan, Musyarapah : Studi Living Qur'an Tentang Pengaruh Bacaan Surah Al-Fatihah Bagi Anak Yang Sering Tantrum

ketika seseorang melakukan suatu tindakan tanpa memikirkan akibat dari apa yang dilakukannya), agresifitas, menentang, merusak yang bersifat menetap adalah kondisi patologis anak yang memerlukan penanganan segera agar terhindar dari segala resiko cedera anak dan ketegangan keluarga.

Jadi dapat disimpulkan study living Qur'an tentang penerapan pembacaan Al-Fatihah pada anak tantrum ini memberi banyak manfaat, yaitu : emosi anak bisa stabil dan lebih tenang setelah dibacakan surat Al-Fatihah, meningkatkan konsentrasi belajar dan mencerdaskan anak, anak mampu berinteraksi lebih baik, anak lebih mandiri, anak lebih ceria dan jarang menangis, anak bersikap lebih positif, sistem kekebalan tubuhnya semakin baik.

\section{DAFTAR PUSTAKA}

Ansyah, Eko Hardi, and Cholichul Hadi. "PSIKOLOGI AL-FATIHAH: Solusi untuk Mencapai Kebahagiaan yang Sebenarnya" 4, no. 2 (2017).

Asti Musman. Berdamai Dengan Emosi Kenali Emosi Hadapi Hidup. Yogyakarta: Anak Hebat Indonesia, 2018.

Dr. Ahmad 'Ubaydi Hasbillah, MA. Hum. Ilmu Living Qur'an-Hadis Ontologi. Epistemologi Dan Aksiologi. Cet. 3. Banten: Yayasanl Wakaf Darus-Sunnah, 2021.

Evi Julianur. Wawancara Tentang Penerapan Pembacaan Al-Fatihah Pada Anaknya, November 18, 2021.

Fahrun Nisa. "Terapi Kesehatan Dengan Menggunakan Ayat-Ayat Al-Qur'an di Rumah Pengobatan K.H. Misbahuddin Ali Desa Benda Kecamatan Sirampog Kabupaten Brebes." IAIN Purwokerto, 2020.

Hayes, Eileen. Seri Panduan Praktis Keluarga Tantrum Panduan Memahami Dan Mengatasi Ledakan Emosi Anak Diterjemahksn Oleh Wahyuni R. Kamah. Jakarta: Erlangga, 2003.

Ibnu Katsir. Mudah Tafsir Ibnu Katsir 1 Al-Fatihah s.d. Al-Baqarah Shahih, Sistematis, Lengkap Diterjemahkan Oleh DR. Engkos Kosasih, Lc., M. Ag. Jakarta: Maghfirah Pustaka, 2016.

In Mutiara, Innayah. Wawancara Tentang Penerapan Pembacaan Al-Fatihah Pada Anaknya, November 28, 2021.

Izzatul Fithriyah, Yunias Setiawati, Sasanti Yuniar. "Mengatasi Temper Tantrum Pada Anak Prasekolah.” Universitas Airlangga, 2019.

Lestari, Astri. “Terapi Al-Qur'an Bagi Anak Autisme Di Sekolah Khusus Taruna Al-Qur'an Ngaglik, Sleman, Yogyakarta Skripsi Diajukan untuk Memenuhi Persyaratan Memperoleh Gelar Sarjana Agama (S.Ag)," n.d.

Lestari, Fuji. “Al-Qur'an Dan Penyembuhan (Studi Living Qur'an tentang Praktek Pengobatan Alternatif Bengkel Menungso di Dusun Jaten Kelurahan Pedurungan Tengah Kecamatan Pedurungan Semarang) Tesis.” Semarang : IAIN Walisongo, 2018.

Mabaji, Gau. "UNDERSTANDING TANTRUM BEHAVIOR AND HOW TO SOLVE IT" 18, no. 02 (2013): 10.

Al Qalam: Jurnal Ilmiah Keagamaan dan Kemasyarakatan Vol. 16, No. 2

Maret - April 2022 
Desty Angga Wulan, Musyarapah : Studi Living Qur'an Tentang Pengaruh Bacaan Surah Al-Fatihah Bagi

Anak Yang Sering Tantrum

Muhammad Muhyidin. Hidup Di Pusaran Al-Fatihah Mengungkap Keajaiban Konstruksi Ummul Kitab. Bandung: Mizania, 2008.

Muhammad Rasyid Ridha. Tafsir Al-Fatihah Menemukan Hakikat Ibadah Diterjemahkan Dari Tafsir Al-Fatihah wa Sittu Suwar min Khawatim Al-Qur'an: Al-'Ashr wa Al-Kautsar, wa Al-Kafirun, wa Al-Ikhlash, wa Al-Mu'awwidzatain Diterjemahkan Tiar Anwar Bachtiar. Cet. 4. Bandung: Al-Bayan Mizan, 2007.

Nur Azizah, Rochmah. "Tradisi Pembacaan Surat Al-Fatihah Dan Al-Baqarah (Kajian Living Qur'an di PPTQ, 'Aisyiyah, Ponorogo)." STAIN Ponorogo, 2016.

"Pembacaan Surat Al-Fatihah Dalam Tradisi Mujahadah Malam Jumat Studi Living Qur'an Di PP Al-Imdad II Pajangan Bantul," n.d.

Qaris Tajuddin. Mengarungi Samudera Al-Fatihah. Jakarta: Kukuruyuk, 2019.

Rida Sucinindyasputeri, Citra Indriani Mandala, Anisah Zaqiyatuddini, Andi Muhammad Aditya S. "Pengaruh Terapi Zikir Terhadap Penurunan Stress Pada Mahasiswa Magister Profesi Psikologi." Universitas Islam Indonesia, 2017.

Rubino, Dr. "Pengobatan Berbagai Penyakit dengan Ayat-Ayat Al-Qur'an." Universitas Medan Area, 2019.

Sayyid Muhammad Syatha, Shekh. Di Kedalaman Samudera Al-Fatihah Menyingkap Tabir Makna-Makna Dan Hikmah-Hikmah-Hikmah Surah Paling Akrab Damalm Hidup KIta ; Surah Al-Fatihah. Medan: Mirqat, 2008.

Setiadi Ihsan. Al-Fatihah : Model Sistem Kehidupan Muslim. Cet. 1. Yogyakarta: Deepublish, 2020.

Sugiyono. Metode Penelitian Kuantitatif Kualitatif Dan $R \& D$. Cet. 2. Bandung: CV. Alfabeta, 2019.

Supradewi, Ratna. "Efektivitas Pelatihan Dzikir untuk Menurunkan Afek Negatif pada Mahasiswa," n.d.

Syaikh Imam Al-Hafiz, Imaduddin Abul Fida Ismail ibnul Khatib, Abu Hafs Umar ibnu Katsir. Samudera Al-Fatihah, Al-Ikhlas, Al-Falaq Dan An-Naas Tafsir Ibnu Katsir Dan Jalalain. Jakarta: Shahih, 2015.

Zaman, Akhmad Roja Badrus. "Living Qur'an Dalam Konteks Masyarakat Pedesaan (StudiI Pada Magisitas Al-Qur'an Di Desa Mujur Lor, Cilacap)” 24, no. 2 (2020).

Al Qalam: Jurnal Ilmiah Keagamaan dan Kemasyarakatan Vol. 16, No. 2

Maret - April 2022 